\title{
UJI AKTIVITAS ANTIOKSIDAN FRAKSI ETIL ASETAT DAUN WUNGU (Graptophyllum pictum (Linn) Griff) DENGAN METODE FRAP (FERRIC REDUCING ANTIOXIDANT POWER)
}

\author{
Aminah, A. Muflihunna, Zainal Abidin \\ Fakultas Farmasi Universitas Muslim Indonesia, Makassar \\ Email : Aminah.aminah@umi.ac.id.
}

\begin{abstract}
'Wungu' leaf is a plant known to contain flavonoids as the antioxidant. Thisresearch aimed to determine the antioxidant activit ethyl acetace fraction of 'Wungu' leaf (Graptophyllum pictum (Linn) Griff) by Ferric Reducing Antioxidants Power (FRAP) method. Extraction by maceration method usingethanol $96 \%$. Extract partitioned with ethyl acetace and water. Thefiltrate was dried with rotary evaporator and produce ethyl acetace fraction. Fraction were analyzed quantitatively by FRAP method with potassium ferriccyanide reagent solution, phosphate buffer, ferricchloride and distillede water. The sampel solutions analyzed by UV-vis spectrophotometer at a maximum wavelength of $705 \mathrm{~nm}$ using kuarsetin solution as a standard. The result showed that the antioxidantactivity of ethyl acetate fraction of 'wungu'(Graptophyllum pictum (Linn) Griff) is $3.984 \times 10^{-6} \mathrm{~g}$ QE/g fraction.
\end{abstract}

Keywords : Antioxidant, ethyl acetate fraction Wungu leaf, FRAP method.

\section{PENDAHULUAN}

Penggunaan senyawa antioksidan semakin berkembang, baik untuk makanan maupun pengobatan seiring dengan bertambahnya pengetahuan tentang radikal bebas. Banyak tumbuhan yang berpotensi sebagai obat-obatan salah satunya yang bermanfaat melindungi tubuh manusia dari bahaya radikal bebas ${ }^{(1)}$.

Sebagai Negara yang memiliki kekayaan flora nomor dua di dunia, Indonesia diyakini memiliki berbagai macam tumbuhan yang dapat dimanfaatkan sebagai obat, salah satunya adalah daun wungu. Ada 3 tiga varietas, yaitu berdaun ungu, berdaun hijau dan belang-belang putih. Varietas yang digunakan sebagai obat adalah varietas berdaun ungu. Daun wungu biasanya digunakan dalam pengobatan diuretik (batang atau daunnya), melancarkan haid (bunganya) dan daunnya digunakan untuk pengobatan anti inflamasi, melembutkan kulit, sembelit, ambeien, reumatik, bisul dan pencahar ringan). Daun wungu (Graptophyllum 
pictum (Linn) Griff) diketahui mengandung flavonoid, saponin, tannin, alkaloid dan steroid ${ }^{(2)}$.

Salah satu golongan kandungan kimia yang banyak berfungsi sebagai zat aktif yang dapat dimanfaatkan sebagai pengobatan adalah flavonoid. Flavonoid dapat dikonsumsi secara teratur untuk meningkatkan usia harapan hidup karena flavonoid dapat mereduksi inflamasi dan penyakit jantung coroner $^{(3)}$.

Berdasarkan hal tersebut maka akan dilakukan penelitian aktivitas antioksidan fraksi etil asetat daun wungu (Graptophyllum pictum (Linn) Griff) dengan metode FRAP. Dimana prinsip dari uji FRAP adalah reaksi transfer elektron dari antioksidan senyawa $\mathrm{Fe}^{3+}$ menjadi $\mathrm{Fe}^{2+}$. Kelebihan dari metode FRAP adalah metodenya yang murah, cepat, dan reagen yang digunakan cukup sederhana serta tidak menggunakan alat khusus untuk menghitung total antioksidan ${ }^{(4)}$.

\section{METODE PENELITIAN}

\section{Alat yang Digunakan}

Alat-alat yang digunakan adalah mikropipet (Mammert ${ }^{\circledR}$ ), Rotary vacuum evaporator (Ika® $\mathrm{RV} \quad 10$ basic), spektrofotometer UV-vis (Apel®,PD 303 UV), timbangan analitik
(Acis AD-600H), Sentrifuge (Onemed), tabung sentrifuge ( Pyrex).

\section{Bahan yang Digunakan}

Bahan-bahan yang digunakan pada penelitian ini adalah ekstrak etanol daun wungu (Graptophyllum pictum (Linn) Griff), aquades, Kuarsetin, Asam trikloroasetat $1 \%$,

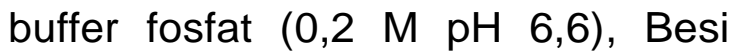
klorida $\left(\mathrm{FeCl}_{3}\right) \quad 0,1 \%$, Kalium Ferri sianida $\left(\mathrm{K}_{3} \mathrm{Fe}(\mathrm{CN})_{6}\right.$.

\section{Tahap Penelitian}

\section{Pengambilan dan Pengolahan sampel}

Sampel daun wungu (Graptophyllum pictum (Linn) Griff) dibersihkan dari kotoran yang melekat pada daun menggunakan air mengalir lalu dikeringkan dengan cara dianginanginkan. Setelah kering sampel dipotong-potong kecil, kemudian siap untuk diekstraksi dengan metode maserasi.

Ekstraksi sampel daun wungu (Graptophyllum pictum (Linn) Griff)

Sampel berupa daun wungu (Graptophyllum pictum (Linn) Griff) sebanyak 200 gram dimasukkan ke dalam wadah maserasi, lalu ditambahkan pelarut etanol $96 \%$ hingga $3 \mathrm{~cm}$ diatas simplisia, dibiarkan selama 3 hari dalam bejana tertutup dan terlindung dari cahaya matahari langsung sambil diaduk secara 
Uji Aktivitas Antioksidan Fraksi Etil Asetat Daun Wungu (Graptophyllum pictum (Linn) Griff) Dengan Metode FRAP (Ferric Reducing Antioxidant Power)

periodik, setelah $3 \times 24$ jam dilakukan penyaringan dan ampasnya dimaserasi kembali dengan cairan penyari yang baru. Maserasi dilakukan sebanyak 3 kali dan diperoleh ekstrak etanol. Hasil penyarian yang diperoleh kemudian diuapkan dan diperoleh ekstrak etanol kental.

Pembuatan fraksi etil asetat daun wungu

Ekstrak etanol yang diperoleh diambil sebanyak 20 gram untuk diekstraksi dengan pelarut etil asetat dengan cara partisi cair-cair. Ekstrak etanol sebanyak 20 gram disuspensikan dengan air sebanyak 20 $\mathrm{ml}$ kemudian dikocok, dan ditambahkan $20 \mathrm{ml}$ etil asetat lalu dikocok, didiamkan selama 30 menit sampai terjadi pemisahan antara lapisan etil asetat (fraksi etil asetat) dan lapisan air (residu). Residu dipartisi kembali sesuai dengan cara di atas, dilakukan berulang hingga jernih. Lapisan fraksi etil asetat dikumpulkan dan diuapkan hingga diperoleh fraksi etil asetat.

\section{Penyiapan pada sampel}

Fraksi etil asetat daun wungu ditimbang dengan 3 replikasi yaitu masing-masing $10 \mathrm{mg}$. Masing-masing fraksi dilarutkan dengan etanol $96 \%$ sebanyak $10 \quad \mathrm{~mL}$ kemudian dihomogenkan.
Pembuatan larutan dan penentuan antioksidan total

\section{Larutan Dapar fosfat 0,2 M pH 6,6}

Larutan disiapkan dengan menimbang 2 gram $\mathrm{NaOH}$ dan dilarutkan dengan aquades bebas $\mathrm{CO}_{2}$ hingga tepat $250 \mathrm{~mL}$ dalam labu takar. Kemudian sebanyak 6,8 gram $\mathrm{KH}_{2} \mathrm{PO}_{4}$ yang dilarutkan dengan aquades bebas $\mathrm{CO}_{2} 250 \mathrm{~mL}$ dalam labu takar. Kemudian dipipet sebanyak 16,4 mL $\mathrm{NaOH}$ dimasukkan dalam labu takar dan dicampurkan $50 \mathrm{~mL} \quad \mathrm{KH}_{2} \mathrm{PO}_{4}$, selanjutnya diukur sampai $\mathrm{pH}$ 6,6 dan dicukupkan dengan aquades bebas $\mathrm{CO}_{2}$ hingga $200 \mathrm{~mL}$.

\section{Larutan $\mathrm{FeCl}_{3} \mathbf{0 , 1} \%$}

Larutan disiapkan dengan melarutkan 0,1 gram $\mathrm{FeCl}_{3}$ dalam aquades dan diencerkan dalam labu takar $100 \mathrm{~mL}$.

\section{Larutan asam trikloroasetat $10 \%$}

Larutan disiapkan dengan melarutkan 10 gram TCA dalam aquades dan diencerkan dalam labu takar $100 \mathrm{~mL}$.

\section{Pembuatan Blanko}

Larutan etanol 96\% dimasukkan dalam labu ukur sebanyak $1 \mathrm{~mL}$ ditambahkan $1 \mathrm{~mL}$ dapar fosfat $0,2 \mathrm{M}$ $(\mathrm{pH} 6,6)$ dan $1 \mathrm{~mL}\left(\mathrm{~K}_{3} \mathrm{Fe}(\mathrm{CN})_{6} \quad 1 \%\right.$ setelah itu ditambahkan $1 \mathrm{~mL}$ aquades dan $0,5 \mathrm{~mL} \mathrm{FeCl}_{3} \quad 0,1 \%$ dan diukur absorbansinya pada panjang 
Uji Aktivitas Antioksidan Fraksi Etil Asetat Daun Wungu (Graptophyllum pictum (Linn) Griff) Dengan Metode FRAP (Ferric Reducing Antioxidant Power)

gelombang maksimum $705 \mathrm{~nm}$ pada spektrofotometer UV-Vis.

\section{Pembuatan kurva baku}

Larutan stok 1000 ppm dibuat dengan melarutkan $25 \mathrm{mg}$ kuarsetin yang dilarutkan dengan etanol $96 \%$ hingga batas labu ukur $25 \mathrm{ml}$. Selanjutnya dari larutan stok 1000 ppm diambil masing-masing 0,7, 0,9, 1,0 dan $1,3 \mathrm{~mL}$ ditempatkan dalam labu ukur $25 \mathrm{~mL}$ yang berbeda dan diencerkan dengan etanol 96\% hingga $25 \mathrm{~mL}$ dan dihomogenkan, dipipet 1 $\mathrm{mL}$, ditambahkan $1 \mathrm{~mL}$ dapar fosfat $0,2 \mathrm{M}(\mathrm{pH} 6,6)$ dan $1 \mathrm{~mL}\left(\mathrm{~K}_{3} \mathrm{Fe}(\mathrm{CN})_{6}\right.$ $1 \%$ setelah itu diinkubasi selama 20 menit dengan suhu $50^{\circ} \mathrm{C}$. Ditambahkan $1 \mathrm{~mL}$ aquades dan 0,5 $\mathrm{mL} \mathrm{FeCl}_{3}, 0,1 \%$ setelah itu diinkubasi dan diukur absorbansinya pada panjang gelombang maksimum 705 $\mathrm{nm}$ pada spektrofotometer UV-Vis. Konsentrasi larutan standar 1000 ppm kuarsetin yakni 70, 90, 110, dan 130 ppm.

\section{HASIL DAN PEMBAHASAN}

Tabel 1. Hasil pengukuran serapan larutan pembanding kuarsetin dengan spektrofotometer UV-Vis pada panjang gelombang maksimum $705 \mathrm{~nm}$.

\begin{tabular}{cc}
\hline Konsentrasi (ppm) & Absorban \\
\hline 70 & 0,250 \\
90 & 0,427 \\
110 & 0,647 \\
130 & 0,717 \\
\hline
\end{tabular}

\section{Uji aktivitas antioksidan dengan metode FRAP}

Sebanyak $10 \mathrm{mg}$ fraksi dilarutkan dalam $10 \mathrm{~mL}$ etil asetat, lalu dipipet $1 \mathrm{~mL}$, ditambahkan $1 \mathrm{~mL}$ dapar fosfat $0,2 \mathrm{M}(\mathrm{pH}$ 6.6) dan $1 \mathrm{~mL}$ $\mathrm{K}_{3} \mathrm{Fe}(\mathrm{CN})_{6} \quad 1 \%$ setelah itu,diinkubasi selama 20 menit dengan suhu $50^{\circ} \mathrm{C}$. Setelah diinkubasi ditambahkan $1 \mathrm{~mL}$ TCA lalu disentrifuge dengan kecepatan 3000 rpm selama 10 menit. Setelah disentifuge dipipet $1 \mathrm{~mL}$ lapisan bagian atas kedalam tabung reaksi, dan ditambahkan $1 \mathrm{~mL}$ aquades dan $0,5 \mathrm{~mL} \mathrm{FeCl}_{3} \quad 0,1 \%$ setelah itu diinkubasi dan diukur absorbansinya pada panjang gelombang maksimum 705 nm. Kurva kalibrasi dibuat menggunakan larutan kuarsetin dengan konsentrasi 70, 90, 110, dan 130 ppm.

\section{Analisis data \\ Analisis data menggunakan persamaan regresi kurva standar dengan persamaan linear $y=b x+a$.}


Tabel 2. Hasil pengukuran absorbansi dan nilai aktivitas antioksidan fraksi etil asetat daun wungu (Graptophyllum pictum (Linn) Griff).

\begin{tabular}{ccc}
\hline Fraksi etil asetat daun wungu & $\begin{array}{c}\text { Absorbansi } \\
(\mathbf{7 0 5} \mathbf{~ n m})\end{array}$ & $\begin{array}{c}\text { Aktivitas antioksidan } \mathbf{( g} \\
\mathbf{Q E} / \mathbf{g} \text { fraksi) }\end{array}$ \\
\hline Replikasi I & 0,315 & $3,846 \times 10^{-6}$ \\
Replikasi II & 0,345 & $4,031 \times 10^{-6}$ \\
Replikasi III & 0,352 & $4,075 \times 10^{-6}$ \\
\hline
\end{tabular}

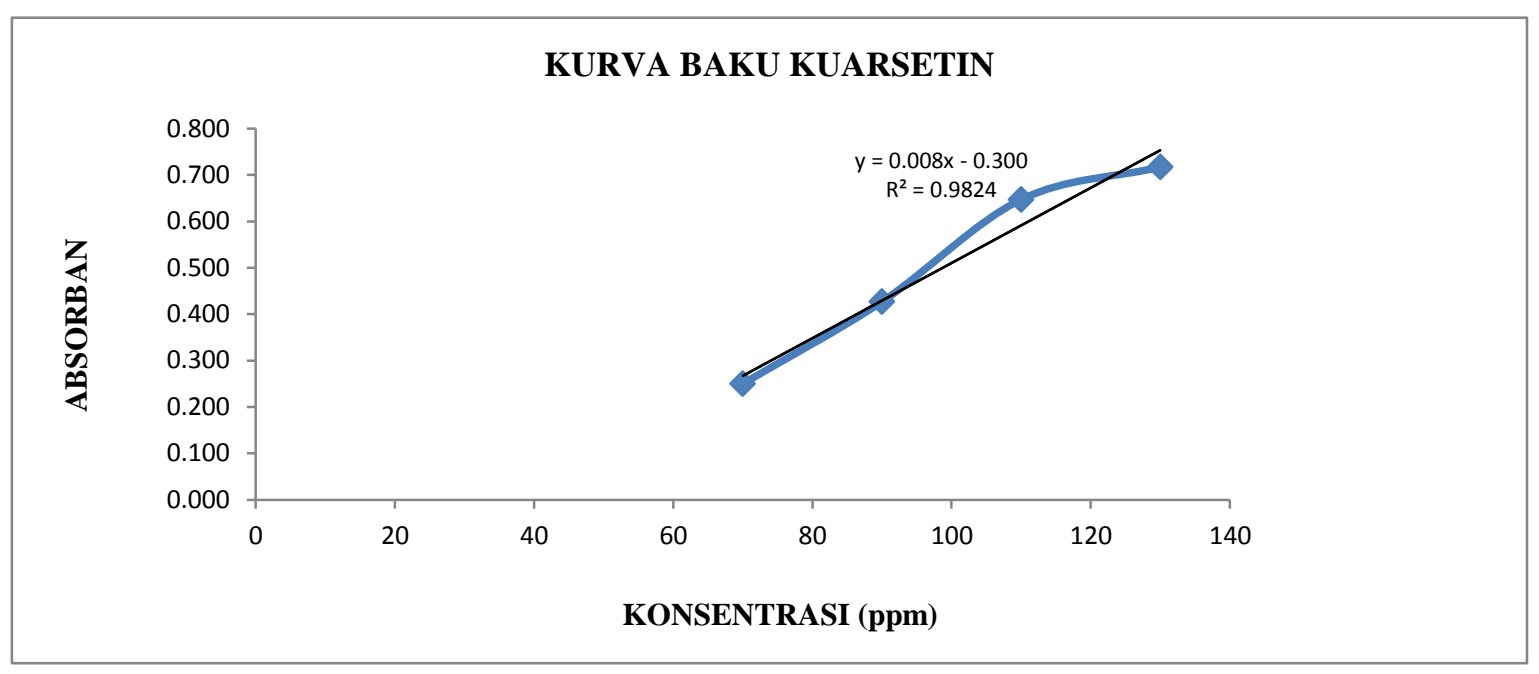

Gambar 1. Kurva Hubungan antara konsentrasi kuarsetin dengan absorbansi

Hasil pengamatan diperoleh replikasi pertama, absorbansi sampel fraksi etil asetat daun wungu adalah 0,315 dengan aktivitas antioksidan

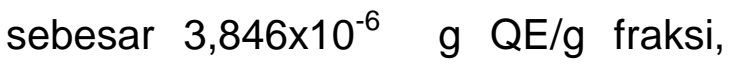
untuk replikasi kedua absorbansi sampel adalah 0,345 dengan aktivitas antioksidan sebesar $4,031 \times 10^{-6} \mathrm{~g}$ QE/g fraksi, Untuk replikasi ketiga, absorbansi sampel adalah 0,352 dengan aktivitas antioksidan sebesar $4,075 \times 10^{-6} \mathrm{~g}$ QE/g fraksi. Dengan nilai rata-rata dari sampel fraksi etil asetat daun wungu (Graptophyllum pictum

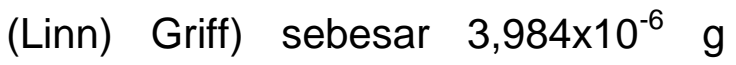
$\mathrm{QE} / \mathrm{g}$ fraksi. Artinya dalam setiap gram fraksi setara dengan 3,984 $\mathrm{g}$ kuarsetin.

\section{KESIMPULAN}

Berdasarkan pengujian yang telah dilakukan maka diperoleh hasil aktivitas antioksidan fraksi etil asetat daun wungu (Graptophyllum pictum (Linn) Griff) dengan metode FRAP dengan pembanding kuarsetin diperoleh sebesar $3,984 \times 10^{-6} \mathrm{~g}$ QE/g fraksi.

\section{DAFTAR PUSTAKA}

1. Trilaksani W. Antioksidan: jenis, sumber, Mekanisme Kerja dan Peran Terhadap Kesehatan, Insititut Pertanian Bogor : Bogor, 2003. 
Uji Aktivitas Antioksidan Fraksi Etil Asetat Daun Wungu (Graptophyllum pictum (Linn) Griff) Dengan Metode FRAP (Ferric Reducing Antioxidant Power)

2. Arifatin LR. Kajian Flavonoid Daun Graptophyllum pictum Linn Griff (Daun Wungu) Sebagai Analgesik dan Antiinflamasi Pada tikus (Skripsi). Jurusan Biologi FMIPA Unibraw : Malang, 1999.
3. Gandjar IG dan Rohman. Kimia Analisis Farmasi. Pustaka Pelajar: Yogyakarta, 2007.

4. Selawa W, Runtuwene MRJ dan Citraningtyas G. Kandungan flavonoid dan kapasitas antioksidan total ekstrak etanol daun binahong. 2013 . 